\title{
Is the Meaning of the "Sharing Economy" Shared Among Us? Comparing the Perspectives of Japanese and Swedish Researchers
}

\author{
Takashi Majima $^{1}$ D $\cdot$ Per Fors $^{2} \cdot$ Yu Inutsuka $^{3} \cdot$ Yohko Orito $^{4}$
}

Received: 5 October 2020 / Accepted: 7 February 2021 / Published online: 22 February 2021

(c) Springer Japan KK, part of Springer Nature 2021

\begin{abstract}
In this paper, we aim to investigate how researchers in Japan and Sweden perceive and approach the term "sharing economy" in research publications. Systematic literature reviews were used to explore academic discussions in both countries. The main finding of this research is that although researchers in both contexts use similar definitions and concepts, the meanings and connotations of the sharing economy differ among the two contexts. In summary, Japanese researchers tend to focus first and foremost on the economic effects of the sharing economy, as it serves the purpose of economic revitalisation. In contrast, Swedish researchers focus on its environmental effects. The differences reflect country-specific socio-cultural, technological, and economic contexts. Finally, we suggest future directions for research and policy development.
\end{abstract}

Keywords Sharing economy · Collaborative consumption · Rashomon-like reality · Systematic literature review

Takashi Majima

t-majima@isc.senshu-u.ac.jp

Per Fors

Per.Fors@angstrom.uu.se

Yu Inutsuka

inutsuka@nitech.ac.jp

Yohko Orito

orito.yohko.mm@ehime-u.ac.jp

1 Senshu University, Kawasaki, Japan

2 Uppsala University, Uppsala, Sweden

3 Nagoya Institute of Technology, Nagoya, Japan

4 Ehime University, Matsuyama, Japan 


\section{Introduction}

The term sharing economy was coined in the mid-2010s and has since then been extensively researched, embraced by policymakers, and widely discussed by the general public. Despite the fact that many authors who write about the sharing economy use similar definitions and sources, it is clear that the sharing economy is not "a thing", but rather a concept that allows of many different interpretations (see Corvellec et al. [1]). However, there is a general consensus that the sharing economy can improve the economic, environmental, and social aspects of society. For example, Sundararajan [2] emphasises the expected economic benefits; Schor [3] highlights the environmental benefits; whereas Rifkin [4], Belk [5], and Morioka [6] focus on ecological and social rather than economic effects. Furthermore, although authors are generally positive about the sharing economy and the expected outcomes of it, others disagree on what the sharing economy in fact is (and is not), and are concerned about potential rebound effects, negative impacts, risks, and backlashes. New concepts are often assigned various meanings depending on the interests of the actors involved (e.g., [7, 8]); also, the sharing economy is interpreted against a background of different socio-cultural, technological, and economic contexts. In other words, the sharing economy is a "Rashomon-like reality" [9, 10]. Rashomon is a movie directed by Akira Kurosawa of Japan in 1950, and the theme is that individuals perceive the same situation, event or object differently, based on their desires, greed and vanity. ${ }^{1}$ There are no objective facts independent of the observers (the characters of the movie), but "reality" is instead by them perceived in many (ambiguous) ways [9]. Thus, reality depends on the context of the observer. The sharing economy can be interpreted as a Rashomon-like reality; the characters are researchers, journalists, politicians, entrepreneurs, and consumers. Corvellec et al. [1] recently presented a similar idea, namely that the circular economy should be viewed as an empty or floating signifier, allowing for creative interpretations of the original concept by various actors.

To understand how different people perceive the sharing economy, and whether or not cultural factors contributed to this perception, we decided to do a comparative study on how the sharing economy was presented by researchers, policymakers, and politicians in Sweden and Japan, respectively. In this first paper out of two, we focus on how the sharing economy is understood by researchers in Sweden and Japan. ${ }^{2}$ This paper is based on two systematic literature reviews, where papers published by Swedish and Japanese researchers were reviewed. We can conclude that although Swedish and Japanese researchers use similar definitions of the sharing economy, there are many differences concerning the underlying assumptions related to and understandings of the concept.

The paper is structured as follows: Sect. 2 describes the methodological approaches used. Sections 3 and 4 discuss the results of quantitative and qualitative

\footnotetext{
1 This movie is based on two famous Japanese novels written by Ryunosuke Akutagawa. In Rashomon, each character perceives the death of a samurai differently.

${ }^{2}$ In the second paper, we focus on the views of policymakers and politicians [11].
} 
surveys exploring understanding of the sharing economy in the Japanese and Swedish academic contexts, respectively. Sections 5 and 6 are the discussion and the conclusions, respectively.

\section{Methodology}

Snyder [12] showed that knowledge production by business-related research is accelerating greatly, but is fragmented. It is difficult to stay at the leading edge of research, and to access the assumptions in play within, and the general understanding of, a particular research area or concept. Snyder [12] thus argues that literature review is a valuable field of research. Almost all new research is based on previous knowledge. However, timely review is becoming increasingly difficult, given the pace of publication. Also, the assumptions made within, and the understanding of, a particular research field vary regionally. We thus performed two independent systematic literature reviews. We examined the vast majority of all academic articles, book chapters, and masters' theses (available in full-text in specific databases) published (or supervised) by researchers in Japan and Sweden. We explored how Japanese and Swedish researchers viewed for example the definitions, values, and positive and negative effects of the sharing economy. Our literature review was both quantitative and qualitative. We recorded the year of publication, disciplinary background of the researcher, the methodology, the estimated effects, and the types of sharing investigated. Qualitatively, we interpreted the effects, and the underlying meanings and values imbued in the concept. The sources used are described below. Although a literature review facilitates an understanding of the sharing economy as perceived by researchers in Japan and Sweden; many limitations remain. Our research is the first step towards clarification of the Japanese and Swedish perspectives on this economy. ${ }^{3}$ In future research, it would be beneficial to complement this literature review with empirical research based on qualitative data.

\section{Japan}

We collected only full-text publications (2005-2019) from J-stage, CiNii Articles, and Google Scholar (the latter served as a backup source). J-stage contains the full texts of over 2000 Japanese journals. CiNii Articles contains over 20 million texts (not only research but also business articles). We first counted the numbers of research articles on the sharing economy (quantitative review). We used “シェア1) ング・エコハー” (sharing economy in Japanese) as the keyword. The authors were Japan-based researchers at universities and other research institutions. In addition,

\footnotetext{
3 We focused on how the sharing economy was socially constructed by human actors, but it is also important to consider the effect for that by non-human actors, Actor network theory (ANT) can be employed to this end.
} 
Table 1 Numbers of articles on the sharing economy

\begin{tabular}{llllrrrrrr}
\hline & Search condition & 2013 & 2014 & 2015 & 2016 & 2017 & 2018 & 2019 & Total \\
\hline Google Scholar & None & 0 & 4 & 14 & 78 & 160 & 179 & 159 & 597 \\
CiNii Articles & Free words & 0 & 2 & 15 & 55 & 100 & 113 & 82 & 368 \\
J-stage & Full text & 1 & 2 & 2 & 10 & 29 & 33 & 41 & 120 \\
\hline
\end{tabular}

we read the four most cited books about the sharing economy to get a deeper understanding of the concept from a Japanese perspective.

\section{Sweden}

We collected full-text publications from DiVA or Google Scholar (the latter served as a backup source). We read and categorised 121 research papers and masters' theses written between 2013 and 2019; we sought general trends in research focus and methodology, the empirical focus, and the envisaged effects of the sharing economy. We considered only papers written by Sweden-based researchers and students. DiVA is the repository used by 49 of the largest Swedish research institutions and universities. Google Scholar served as a backup; the keywords were "the sharing economy" and "Sweden". Also, during review, we included Swedish masters' theses, due to the fact that most now prominent researchers first explored the field as subject readers of master theses instead of in research publications.

Below, we present our quantitative and qualitative findings. We captured and compared the expected effects and perceived risks of the sharing economy in the academic worlds of both countries. Although both reviews were similarly performed, we adapted our approach to the research context. First, we searched different databases (CiNii/J-stage and DiVA Portal, respectively). Second, as Japanese researchers commonly publish in Japanese and Swedish researchers generally publish in English, we used Japanese keywords to obtain the Japanese context and English keywords to explore the Swedish context.

\section{The Sharing Economy in Japanese Research}

\subsection{Research on the Sharing Economy in Japan: Quantitative Overview}

Here, we present how the sharing economy is understood and presented by authors in the Japanese research context. Table 1 shows the numbers of papers and articles on the topic. It is evident that Japanese researchers began to take notice of the sharing economy in 2015, and the numbers of articles then increased (particularly from 
2017). ${ }^{4}$ Notably, the sharing economy is studied by those interested in business administration; marketing; economics; information and communication technology; law, municipal politics; local communities; urban planning; and industrial, automotive, and traffic engineering. However, most studies focussed on business administration, politics, and local communities. Although numerous international publications focusing on the sharing economy or related concepts have appeared, many of Japanese researchers do not refer to them (e.g., [3-5, 13]).

\subsection{Research Trend on the Sharing Economy: Qualitative Literature Review}

We selected 50 papers dealing with the sharing economy in Japan and sought trends and characteristics (Table 2). The articles could be divided into six categories: (a) an explanation of the concept (what is the "sharing economy"?); (b) ride-sharing (including car sharing); (c) home-sharing; (d) money sharing (cloud funding); (e) skill-sharing; and, (f) other. Most articles fell under (a), (b), or (c). For example, Yagasaki [14] discusses how to promote home-sharing under a new law. Shiba [15] studies how to encourage consumers to use sharing services (rides and homes) from the viewpoint of trust. Notably, many studies focussed on home or ride-sharing, although the numbers of skill-sharing businesses are greater than those of the former services [16]. Researchers consider that home- and ride-sharing are typical or important service categories in Japan.

Sharing economy research in Japan commenced in about 2015. Most Japanese research views the sharing economy as a tool fostering further economic development. For example, Takahashi [17] notes that the sharing economy is a new (hopeful) "business model", and Shiotani [18] emphasises that the sharing economy is the new optimal "strategy" for the Japanese economy. Kunimi [19] wrote:

We can say that it [sharing business] is also quite promising that businesses can make better use of surplus underused resources in society by efficiently matching their needs through ICT. (p.104).

Japanese researchers do not completely ignore the anti-capitalist view of among others (e.g., Rifkin [4]); however, most perceive the sharing economy or sharing economy business models as a new tools for market capitalism. Very few papers explore or take into consideration potential ecological effects of the phenomenon; however, some papers emphasise its social benefits. For example, some recent studies (e.g., [20-22]) encourage the use of ride-sharing services to solve rural problems caused by reduced public transport, depopulation, and ageing population. Thus, private companies are encouraged to take responsibility of (and profit from) societal functions usually handled by the state. For example, Noda et al. [22] wrote:

The sharing economy is expected to become a new business model in terms of conserving natural resources and coping with the depopulation of Japanese society, which is especially serious in rural mountainous areas. Such areas have difficulty

\footnotetext{
4 The literature survey was conducted as follows. First, CiNii Articles and Google Scholar were subjected to free word searches. J-stage was subjected to a full-text search. The retrievals overlapped.
} 


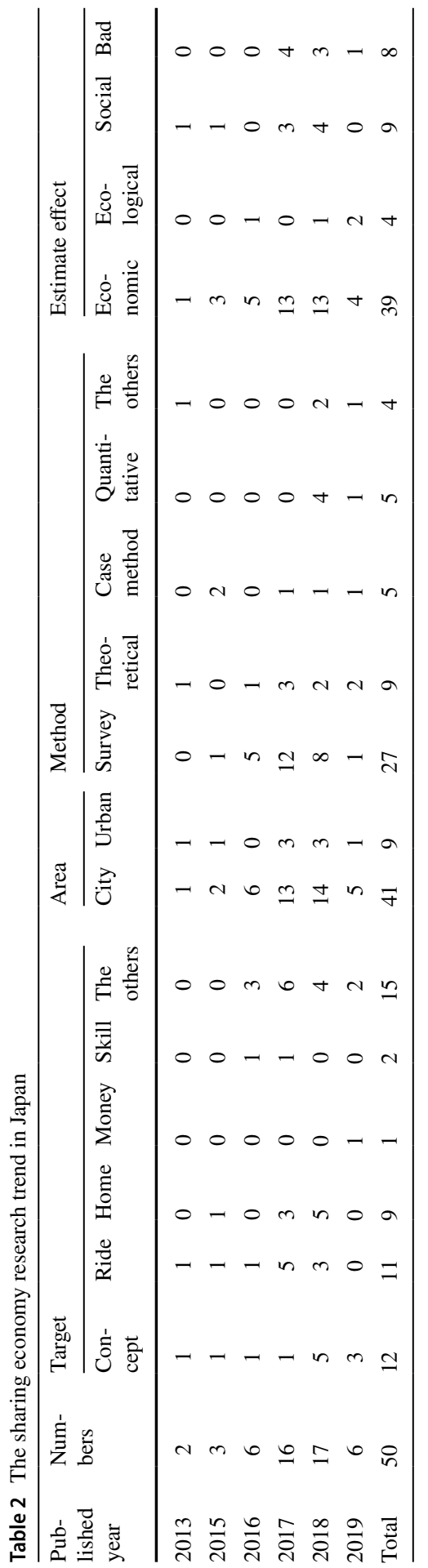


in sustaining their local communities. Therefore, they are hoping that sharing businesses can solve the problem (p.2).

As mentioned above, Noda et al. [22] seemed to view the sharing economy as a tool that would resolve Japanese rural/regional problems. The cited authors introduce sharing services that promote tourism and support parenting established by local governments in Shimabara city (Nagasaki prefecture) and Taku city (Saga prefecture), respectively. Sasaki et al. [23] discuss whether ride-sharing might solve the lack of transportation in rural mountainous areas. Earlier examples are reviewed when creating a suitability test for ride-sharing. Test scores are used to evaluate whether various cities could benefit from ride-sharing, and a pilot implementation is performed in collaboration with a not-for-profit organisation. Ushiba [24] discusses how a regional currency system could revitalise a country town in Kagawa (in the context of sharing business). One interpretation is that Japanese studies tend to reflect the contemporary economic and social situations of Japan.

In terms of research methods, many articles seek to understand the conceptual idiosyncrasies of the sharing economy by reviewing prior research and precedents. Few articles adopt the present theoretical approaches and/or conduct empirical studies. Empirical studies of the sharing economy explore why customers would wish to use sharing businesses [15, 25].

Moreover, most Japanese authors seem to be in favour of the sharing economy and present optimistic views, while very few articles presented negative or critical accounts of the phenomenon. ${ }^{5}$ The challenges imposed by the sharing economy presented by Japanese researchers are usually of economic character and can be categorised as follows ${ }^{6}$ (e.g., [19, 26-33]):

- Cost increases; difficulties in guaranteeing service reliability; environmental concerns; cost monitoring; the need for social infrastructure; and literacy and educational issues.

- Uncertainty of taxation: possible tax/duty impositions on sharing service companies, individuals who provide sharing services; and how to measure such costs.

- Equal footing: fair competition issues; competition for existing companies in the same business (such as the hotel and taxi industries); a tendency to price services higher than sharing economy services can pay.

- Protection of individual service providers; infringement of the rights of individuals who provide sharing economy services as employees; difficulty in defining a private business.

Until 2019, fewer than ten full-length monographs or anthologies on the sharing economy were written by Japanese authors. The topics were those described above.

\footnotetext{
5 In Japanese research papers, an expected negative impact is termed an "external diseconomy". Unlike a "rebound effect", which is a negative side effect, "external diseconomy" seems to focus mostly on economic side effects and not social or environmental.

${ }^{6}$ Few researchers mentioned the risks posed by the architectural control enjoyed by giant platformers who design sharing-economy services using information systems. This is related to the risk of social/ economic disparity caused by utilisation of personal information.
} 
Some authors expect the sharing economy to revitalise the national economy (e.g., [26, 34]). Others (after Rifkin [4]) foresee the development of collaborative communities living in shared urban residences (e.g., [35, 36]). Therefore, Japanese interests are not limited to economic effects or solutions to social problems such as rural depopulation. However, research on environmental effects of the sharing economy is very scarce.

\subsection{The Meaning of the Sharing Economy to Japanese Researchers}

In summary, although many different interpretations of the sharing economy are apparent, and the suggested benefits that such an economy might bring to Japan vary greatly, Japanese researchers generally view the sharing economy as a new tool that will revitalise and redevelop the national economy. This reflects the current Japanese economic situation; the government and business are urgently seeking new economic growth [11]. The sharing economy is regarded as important in terms of revitalising regional economies and solving regional problems caused by an ageing society; it is thought to have the potential to create new collaborative communities in rural areas. Ride-sharing and home-sharing are the principal empirical foci of Japanese research. In terms of sustainability, Japanese researchers generally do not explicitly focus on positive environmental effects. This is surprising, given that Japan led the environmental conservation in Asia (by promoting Green ICT [7]), in line with the Japanese philosophy of mottainai. ${ }^{7}$ Researchers interested in such aspects tend to refer to the circular economy, which seems to be much more associated with environmental effects from the Japanese perspective. Although there is certainly some connection between the sharing economy and a more circular society and industry, this relation is not explored to a large extent within the research community. This might be related to the fact that understandings of the sharing economy in Japan seem to be heavily influenced by commercial actors whose primary focus is not on either circularity or improving the environment.

To some extent, research publications reflect the assumptions about and understandings of the sharing economy in Japan. These publications are to some extent influencing the general opinions about the sharing economy in Japan. However, these publications do not reflect how the concept is understood more generally in Japan, but make up some of many Rashomon-like realities. Further surveys are essential to be able to present more nuanced and accurate accounts [11]. We plan to explore the attitudes and perspectives of other actors, such as the users of sharing economy platforms, and for- and not-for-profit platform providers.

At any rate, although the actual methods of the Japanese sharing economy are under discussion, the discussion of the nature has not been advanced by Japanese researchers, unlike the situation in Sweden as mentioned next section. Our literature review suggests that most Japanese researchers assume that the sharing economy

\footnotetext{
7 A rough translation is: "what a waste!".
} 


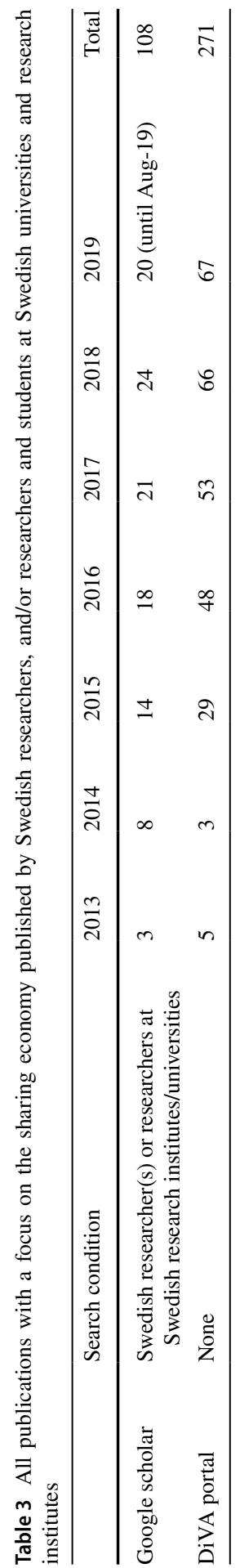


will revitalize the national economy, and focus almost exclusively on how to implement it.

\section{The Sharing Economy in Swedish Research}

\subsection{Research on the Sharing Economy in Sweden: Quantitative Overview}

In Sweden, the sharing economy has been researched since at least 2013 - a couple of years before the phenomenon was explored by Japanese researchers (Table 3).

The sharing economy is researched within and among many scientific disciplines ranging from marketing, management and business to law, urban planning, environmental sciences, and information technology as well as design and human-computer interaction. Many publications embrace two or more of these disciplines, suggesting that research is often interdisciplinary. Methodologically, research tends to be qualitative, although approximately one in ten publications uses primarily quantitative methods to study a particular empirical context. This is comparable to the proportion of publications that are exclusively theoretical, thus discussing the sharing economy on a conceptual level without employing any primary data. In qualitative research papers, a case study approach is the most common. Approximately one in four papers use such an approach (see also Table 4).

\subsection{Research Trend on the Sharing Economy: Qualitative Literature Review}

The literature review revealed that, commonly, the empirical focus was on several different areas (i.e., both car and home-sharing) or was non-specific (other/many). If the focus was on a specific empirical field, this was typically car- and home-sharing, similar to Japanese studies. Most theoretical papers with no or little focus on any particular empirical setting tended to focus on the concept of the sharing economy per se. Such research discussed other things such as "the commons" [37], the concept of "sharing" [38-40], the conceptualisation of sharing-economy roles [41], sharing-economy futures [42-45], the sustainability of the sharing economy [46, 47], cultural barriers and enablers [48, 49], and caring platforms [50, 51].

In Japan, sharing practices in a rural context are thought to revive rural economy; in Sweden, the sharing economy is viewed as principally urban. Of 121 publications, about one-third consider the effects on everyday urban life. Most papers (about twothirds) do not consider whether the perceived effects affect rural or urban dwellers preferentially; several deal exclusively with urban initiatives, albeit not explicitly. Not even one publication explicitly targets rural sharing initiatives.

In terms of the perceived societal effects of sharing economy practices such as car or home-sharing, most publications are optimistic, grounded on the assumption that the sharing economy will positively impact all three dimensions of sustainable development - the economy, the environment, and society. In publications that discuss the impacts of different sharing practices, environmental impacts (i.e., more efficient use of underutilised assets) are usually emphasised, followed by the social 


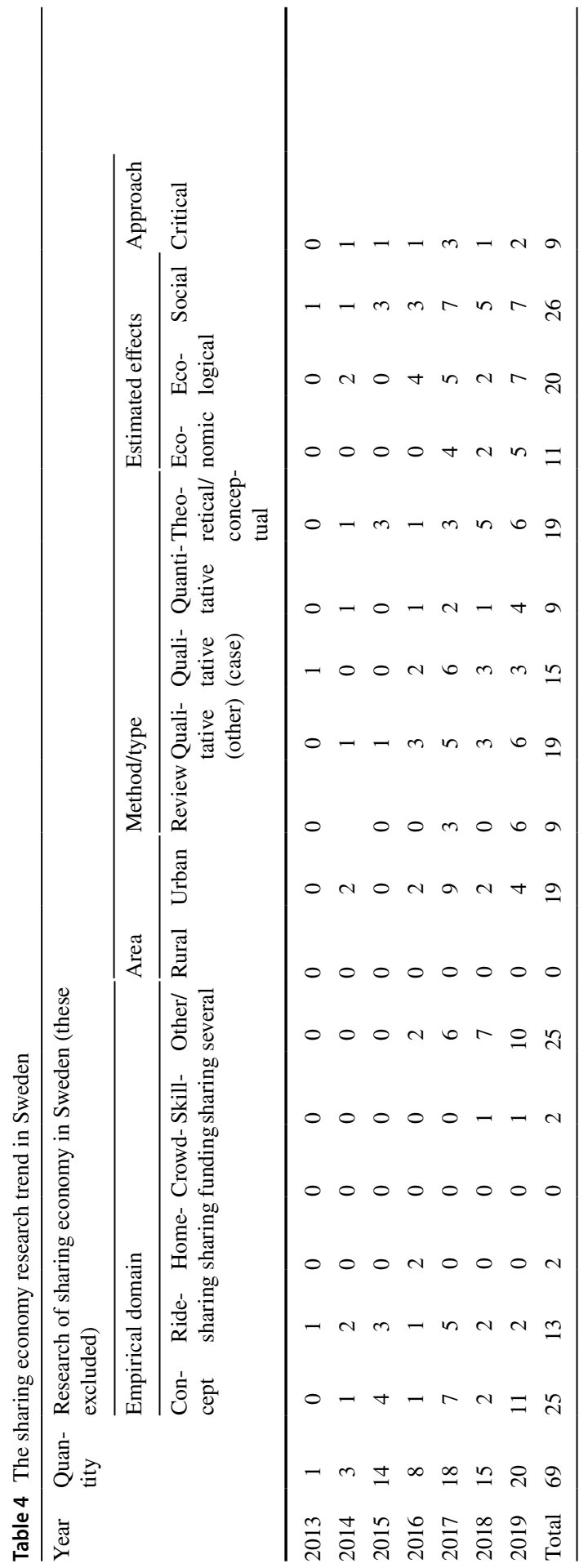


and economic aspects. However, in terms of the societal impacts of the sharing economy, researchers tend to be somewhat critical, given the lack of a clear distinction between private persons and businesses, and any role for the Swedish model in a new business environment. Another source of criticism is how certain researchers and policymakers interpret the concept, and how it is used by commercial actors to falsely promote their operations as sharing (i.e., "share-washing"). Another important aspect that is frequently discussed is the lack of appropriate tax regulation and guidance.

\subsection{Meanings and Values Related to the Sharing Economy of Sweden}

Laurell and Sandström [52], in an analysis of sharing economy discourse on social media, investigate how Swedes understand and reproduce meanings of the sharing economy. The perception of what sharing is spans a variety of both market and nonmarket practices, and is characterised by instability and tension. Furthermore, actors such as Uber, Airbnb and (surprisingly) Tinder dominate the framing of opinions. According to the authors, social media users tend to focus their attention on these actors both when criticising and praising the sharing economy. One explanation for this, according to Laurell and Sandström [52], is that:

Uber and Airbnb on the one hand are perceived and framed by social media users as part of the sharing economy. On the other hand, these actors are subject to resistance by social media users who argue that they should not be understood as part of the phenomenon in question (p. 63).

In our literature review, we encountered many different perceived meanings of the sharing economy. Many researchers compare the sharing economy with "collaborative consumption", "peer consumption", "access-based consumption", "peerto-peer economy", "gig economy", "platform economy", "on-demand economy", and the "circular economy". Although all of these concepts are related (at least to some extent, overlap), different researchers distinguish them in different ways. Some researchers argue that these words and concepts refer to the same phenomenon [53]; others adopt more narrow definitions to highlight certain aspects. For example, while the "sharing economy" emphasises sharing practices, the "gig economy" highlights a form of labour in which the individual providing the product or service is engaged. That being said, not all sharing economy platforms require gig-workers, and not all gig economy platforms facilitate the sharing of underutilised assets. Furthermore, most definitions of the sharing economy mention a digital mediator in the form of a platform. However, not all such platforms facilitate sharing practices; the sharing economy can also be viewed as a subdivision of the platform economy.

As described above, there are many ways by which to conceptualise the sharing economy; this is an important focus among Swedish researchers. This differs markedly from the Japanese situation, where a near-consensus definition (or at least a shared understanding) is in play. Most Swedish researchers are optimistic in terms of the potential of the sharing economy, but not all are content with the sharing practices that are viewed as part of that economy today. Thus, the Swedish research landscape is somewhat critical, depending essentially on how the 
individual researcher conceptualises the sharing economy. We identified different approaches used by researchers to make sense of the concept, associated with the values with which they imbued what they studied.

One approach is that of Kristoffersson [53], who used a rather generous definition of the sharing economy when discussing tax regulation: "[T]he sharing economy refers to online marketplaces for sellers and buyers of goods and services" (p. 221). In the cited work, only Uber and Airbnb serve as examples of sharing economy actors. Such research sometimes emphasises the sustainability potential of the sharing economy, but makes no distinction between different types of actors [48, 54-58].

A second approach also adopts a loose definition of the sharing economy, but emphasises the differences between different actors and their roles in the economy. Bradley and Pargman [37], in an attempt to make sense of the highly diverse actors, argue that sharing economy platforms can be organised in many different ways: "[A] $\mathrm{s}$ for-profit corporations, as for-benefit organisations, as foundations, cooperatives, community groups or through looser informal networks. Some operate on a global scale, others are small and local" (p. 232). The authors generally acknowledge that there are major (and important) differences between the various actors (e.g., [40, 59-61]). Some contributions are rather critical, but not necessarily those that focus on the type of sharing that promotes sustainability.

A third way of making sense of the sharing economy is to accept that there are indeed many different organisations (with different motives) active within the economy, and that these differences make or break the sustainability-related potential of economic initiatives. Examples include the works of Fedosov et al. [62], Pargman et al. [63], and Hult and Bradley [64], who argue that: "[F]ar from all the initiatives undertaken in the name of the collaborative or sharing economy align with ... wider socio-environmental aims" [64, p. 610]. Such a stance generally implies acceptance of different types of sharing economy initiatives including exploitative for-profit initiatives that do not align with sustainability values; and sustainable, non-exploitative not-for-profit activities. Such research sees the sustainability potential of the latter category while criticising the former, albeit acknowledging that many for-profit initiatives indeed promote sharing. Such research emphasises that the raison d'être of the sharing economy is sustainability; this should be promoted.

A fourth approach is related to those described above, but adopts a stricter definition of the sharing economy, usually to distinguish between actual sharing and other (unrelated) practices sometimes promoted as sharing. One common empirical approach is to compare Uber to Blablacar (e.g., [42, 45, 65-67], arguing that Uber does not facilitate increased use of underutilised assets, whereas Blablacar and similar initiatives do. Narrowing of the definitions allows researchers to portray (some) multinational for-profit companies not as sharing economy actors but, rather, as gig, platform, or on-demand economy actors. Guyader [65], in his doctoral thesis, uses the metaphor of the Heart and the Wallet to distinguish between prosocial initiatives of collaborative consumption on one hand, and for-profit activities on the other. He emphasises that some researchers tend to use these concepts interchangeably when they are in fact talking about very different phenomena. Thus, such a position is normative in that it recognises the potential of certain practices in terms of 


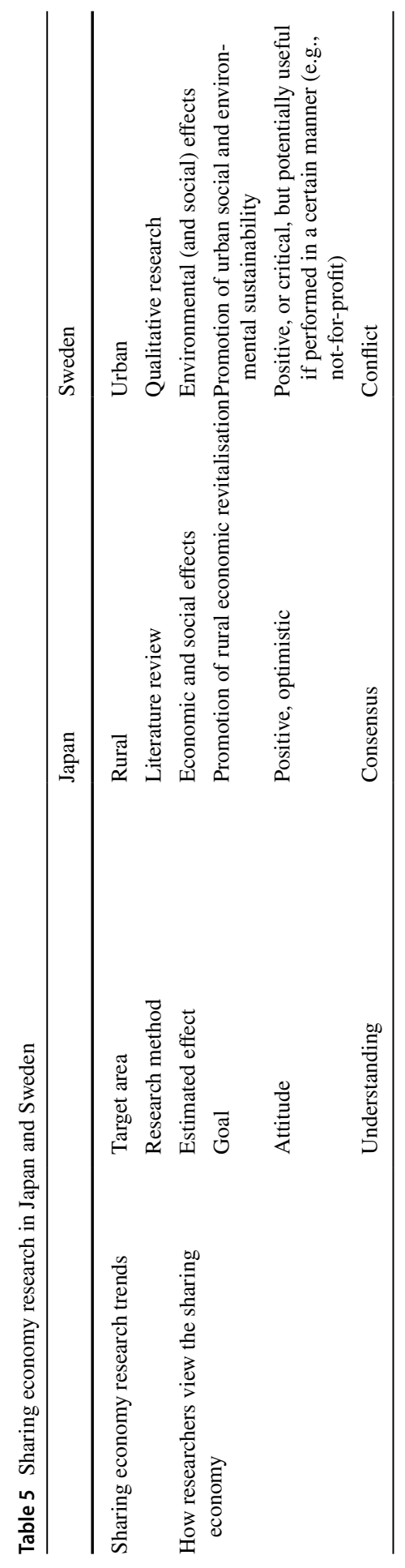


a sustainable future, often in combination with a circular economy $[43,45,59,63$, 68], but regards other practices as mere "share-washing" [66, 69].

\section{Discussion}

As revealed above, sharing economy researchers in Japan and Sweden differ in terms of their research foci and interests. Table 5 compares the research trends of the two countries, and summarises the most obvious differences. ${ }^{8}$ In Japan, the sharing economy is viewed principally as a new way by which to promote economic activities and spur economic growth, i.e., the economic dimension is favoured. On the micro-level, the sharing economy is perceived as a new business model implemented by private companies to make better use of existing underutilised resources. The hoped-for outcomes emphasised in Japan are not commonly discussed in Sweden, i.e., social inclusion of the elderly/youth/men/women, commercialization of traditional "private sphere", "female activities" such as childcare, but also countryside revitalisation, rural public transportation, and solving problems related to depopulation and ageing citizens. Although the perceived risks include taxation uncertainty and architectural control by giant platformers, most researchers are positive and optimistic. Compared to Japan, many more Swedish studies focus on the positive effects of the sharing economy on environmental sustainability (Table 5).

The sharing economy as a concept is more frequently discussed in Sweden than Japan; Swedish researchers often ask what the sharing economy is and what it is not. Some researchers use very general or "open" definitions; others favour narrower definitions to promote the "right kind" of sharing practices. Therefore, despite the fact that the concept of the sharing economy per se is viewed positively (thus something to be promoted), the current state of the "sharing economy" is often criticised by Swedish researchers as being dominated by multinational corporations. In Japan, in contrast, a near-consensus the understanding of what the sharing economy is and should be has emerged (Sect. 3). This understanding is usually based on an assumption of economic growth (e.g., "The Sharing Economy Association"). In other words, Japanese researchers prioritise the practical utility of the sharing economy, while Swedish researchers still ask: "What is the sharing economy?", or "What should the sharing economy be?" In short, Japanese researchers prefer to "leap before you look", but Swedish researchers prefer to "look before you leap".

Why do such differences exist? As suggested above, the answer may be because they reflect the economic, cultural, environmental, and political contexts (history and current life) in the two countries. In particular, the problems faced by the two nations explain some of the differences. The Japanese are very concerned about depopulation and rural devitalisation; both compromise economic growth. Sweden (despite its large per capita environmental footprint) is regularly hailed as a world leader in environmental policy/awareness; it is not surprising that the sharing economy is viewed as a tool to promote environmental sustainability. However, as it

\footnotetext{
${ }^{8}$ The table shows the general (typical) trends of academic research.
} 
remains unclear how today's sharing practices in fact promote sustainability, Swedish researchers disagree on whether environmental benefits are possible. In another paper [11], we identified similar tendencies within the political sphere. There, we argue that although the concept is more-or-less already adapted uniformly adapted in the Japanese context, the Swedish views reflect disagreement rather than consensus within both the political and research spheres.

\section{Conclusions}

We examined how the sharing economy is understood by researchers in two countries, Japan and Sweden. The meaning of the "sharing economy" is not fully shared among researchers either between or within the two countries. When researchers use this term, their understanding of it and the points stressed differ profoundly. Japanese researchers, in general, view the sharing economy as a tool assisting national and regional economic revitalisation. They emphasise that it may reduce the depopulation of rural areas and remedy the shortage of labour force in an ageing society. In contrast, many Swedish researchers regard the sharing economy as phenomenon that can further our efforts towards a more environmentally sustainable society. Environmental issues and the impacts on the societies in general are discussed more explicitly by Swedish researchers than by Japanese researchers. In Japan, the concept of circular economy seems to have many more sustainability-related connotations; however, we have not yet studied this phenomenon in these two contexts yet. Although the meaning of sharing economy has not yet become unified within each country, the understandings are more diverse in Swedish than in Japanese research.

Some implications of our work follow. Despite the use of new phrase, thus the "sharing economy", by members of a globalising society wherein new concepts are rapidly shared; in many cases, we tend to view the concept through the lens of our limited ethnocentric perspectives; we use the same word, but impart different meanings to it. Our study may open a new research path in terms of international comparative work. Japanese researchers can share their pragmatic views with Swedes; Swedish researchers can encourage the Japanese to reflect more on the underlying understandings and assumptions related to the concept. The practical ideas and applications in Japan may inform Swedish researchers. For example, new practitioners in the sharing economy of Japan can suggest novel business ideas (and, of course, define the risks).

A new ambiguous phrase is a Rashomon-like Reality, interpreted by various actors with reference to their intentions and desires. Therefore, it is impossible to predict whether new interpretations of the sharing economy will emerge or whether existing interpretations will be reinforced as researchers in either country begin to respect the view of others on what a sharing economy means. This research work is also an actor in the sense-making process of a phenomenon of the sharing economy. 
To echo an earlier point we made in this paper, the sharing economy is Rashomon-like reality in nature. ${ }^{9}$ We deal here with only the general (but diverse) understandings of the academic world; this is but one aspect of the sharing economy. The "sharing economy" is a relatively a new-born concept; the image and social values thereof vary by country, and change continuously, even in the era of COVID-19. We explored the research situations of only two countries by the year to 2019, and further work is required worldwide. In addition, the views of governmental bodies, business organisations, and consumers should be collected via empirical research and interviews; these will be our next steps.

Acknowledgements This paper was supported by the JSPS/STINT Bilateral Joint Research Project, "Information and Communication Technology for Sustainability and Ethics: Cross-national Studies between Japan and Sweden" (JPJSBP120185411).

\section{References}

1. Corvellec, H., Böhm, S., Stowell, A., \& Valenzuela, F. (2020). Introduction to the special issue on the contested realities of the circular economy. Culture and Organization, 26(2), 97-102.

2. Sundararajan, A. (2016). The sharing economy: The end of employment and the rise of crowd-based capitalism. Cambridge: MIT Press.

3. Schor, J. (2016). Debating the sharing economy. Journal of Self-Governance \& Management Economics, 4(3), 7-22.

4. Rifkin, J. (2014). The zero marginal cost society: The internet of things, the collaborative commons, and the eclipse of capitalism. New York: Palgrave Macmillan.

5. Belk, R. (2014). Sharing versus pseudo-sharing in Web 2.0. The Anthropologist, 18(1), 7-23.

6. Morioka, K. (2018). Is sharing economy a workstyle in the future? Economy, 276, 20-29. (in Japanese).

7. Majima, T., Udagawa, M., Yotsumoto, M., \& Lennerfors, T. (2017). Green IT did not take place: The translation of environmentally friendly IT in Japan. Journal of Information and Management, 37(2), 81-96.

8. Fors, P., \& Lennerfors, T. T. (2013). Translating green IT: The case of the Swedish green IT audit. In First international conference on information and communication technologies for sustainability, February 14-16, ETH Zurich, 208-216.

9. Komori, Y., Noguchi, Y., \& Nomura, N. (Eds.). (1999). The world of narrative therapy. Tokyo: Nihon Hyoronsya Publishing. (in Japanese).

10. Kanai, T., Morioka, M., Takai, T., \& Nakanishi, M. (Eds.). (2009). Between narrating and deceiving: Rashomon-like reality and responsibility of humans. Kyoto: Nakanishiya Publishing. (in Japanese).

11. Fors, P., Inutsuka, Y., Majima, T. \& Orito, Y. (2021). Is the meaning of the "sharing economy" shared among us? Comparing the perspectives of Japanese and Swedish policymakers and politicians. Review of Socionetwork Strategies (in printing).

12. Snyder, H. (2019). Literature review as a research methodology: An overview and guidelines. Journal of Business Research, 104, 333-339.

13. Botsman, R., \& Rogers, R. (2010). What's mine is yours: The rise of collaborative consumption. New York: Harper Collins Publishers.

\footnotetext{
9 Japanese researchers use synonyms of the sharing economy, depending on their needs. For example, when they discuss some sharing businesses (e.g., ride-sharing and skill-sharing) critically, they often use the phrase "gig economy" to describe the businesses [70]. In a sense, this is another example of a Rashomon-like reality.
} 
14. Yagasaki, N. (2017). Current state of affairs, challenges, and outlook for Minpaku from the perspective of tourism. IATSS Review, 42(1), 38-47. (in Japanese).

15. Shiba, K. (2018). Impact of SNS reliability on motivation for using share business: An empirical study on SNS reliability. Annals of the Japan Society for the Study of Business Administration, 88, (10)1-(10)11. (in Japanese).

16. Ministry of Internal Affairs and Communications, Japan. (2018). White paper. https://www.soumu .go.jp/johotsusintokei/whitepaper/ja/h30/pdf/index.html. Accessed 20 Aug 2020. (in Japanese).

17. Takahashi, H. (2017). Change of business model by ICT venture: Focusing on the Uber, Airbnb case studies. The Journal of Science Policy and Research Management, 32(2), 117-127. (in Japanese).

18. Shiotani, S. (2017). Sharing economy: Promoting new platform by trust. Transactions of Japan Foundation for International Tourism, 24, 145-154. (in Japanese).

19. Kunimi, M. (2019). Sharing economy as a new business model: For regulating in the future. Keio Law Journal, 42, 103-120. (in Japanese).

20. Sasaki, K. (2017). Will ridesharing change how people live and move? Ridesharing dreams of cloud mobility. IATSS Review, 42(1), 30-37. (in Japanese).

21. Cho, A., Ma, D., Takahara, I., \& Ohsawa, Y. (2018). Analysis on the matching of ride share caused by transfer. Journal of the City Planning Institute of Japan, 53(3), 597-602. (in Japanese).

22. Noda, T., Tanaka, H., Wang, Y., Izumi, H., Sunami, H., \& Nozawa, K. (2018). Progresses and issues of sharing-economy policy in local areas. Journal of Economics, 45, 1-29. (in Japanese).

23. Sasaki, K., Nigo, K., Yamamoto, M., \& Yotsutsuji, H. (2013). The availability of ride-share as the travel mode for transportation-poor people in low density residential area. Sociotechnica, 10, 54-64. (in Japanese).

24. Usahiba, S. (2019). Consideration to community currency from sharing economy: In case Takamatsu Megurin. Economic Review Shizuoka University, 23(4), 25-38. (in Japanese).

25. Shiba, K. (2015). Development of share business research. Annals of the Japan Society for the Study of Business Administration, 86, 1-9. (in Japanese).

26. Miyazaki, K. (2015). Sharing economy: The world has been changed by Uber and Airbnb. Tokyo: Nihon Keizai Shinbunsha. (in Japanese).

27. Ichikawa, T. (2016). The expectations and issues of the sharing economy. Yamatosokenchosakiho, 24, 36-53. (in Japanese).

28. Okuwada, K., \& Makino, T. (2016). Expansion of sharing economy and its further possibility. Technology and Economy, 592, 27-41. (in Japanese).

29. Sato, R. (2017). The issues on sharing economy. Chosa to Joho, 985. http://dl.ndl.go.jp/info:ndljp/ pid/10992702. Accessed 20 Aug 2020. (in Japanese).

30. Okada, S. (2017). Arguments of sharing economy, Chosa to joho-Issue Brief-983. ndljp/ $\mathrm{pid} / 10983262$. (in Japanese).

31. Negoro, T. (2017). The essentials of sharing economy and its success factors. Nextcom, 30, 4-17. (in Japanese).

32. Fujino, H. (2018). The improvement of productivity in small and medium companies by sharing economy. Shokokinyu, 26-68, https://www.shokosoken.or.jp/chousa/youshi/29nen/29-5.pdf. Accessed 29 Dec 2019. (in Japanese).

33. Tsurusawa, M. (2019). The effect of social capital in the sharing economy: How general trust and social networks solve asymmetric information problems inthe usage of FURIMA smartphone applications. Bulletin of Institute of Current Business Studies, 4, 1-16. (in Japanese).

34. Noguchi, K. (2017). Introduction to sharing economy. Tokyo: Nihon Keizai Shinbunsha. (in Japanese).

35. Miura, A. (2011). Let's talk about "share" for the future of Japan. Tokyo: NHK Publishing. (in Japanese).

36. Ishiyama, A. (2019). Share Life. Tokyo: Cross Media Publishing. (in Japanese).

37. Bradley, K., \& Pargman, D. (2017). The sharing economy as the commons of the 21st century. Cambridge Journal of Regions, 10, 231-247.

38. Lampinen, A. (2015). Deceptively simple: Unpacking the notion of "sharing." Social Media + Society, 1(1), 1-2. https://doi.org/10.1177/2056305115578135.

39. Guyader, H., \& Kienzler, M. (2019). "True Sharing" or "Sharing Economy" Fad? In B. Edvardsson, A. Gustafsson, M. J. Bitner, \& R. Verma (Eds.), QUIS16 symposium: "Advancing Service Research and Practice”, 10-13 June 2019. Sweden: CTF Service Research Center, Karlstad University. 
40. Skågeby, J. (2015). The changing shape of sharing: Digital materiality and moral economies. Discover Society 18. https://discoversociety.org/2015/03/01/the-changing-shape-of-sharing-digitalmateriality-and-moral-economies/. Accessed 19 Aug 2020.

41. Öberg, C. (2018). Roles in the sharing economy. Presented at the ISPIM (International Society for Professional Innovation Management), Innovation Conference 1-13.

42. Bradley, K. (2014). Radio Sweden. https://sverigesradio.se/artikel/5773498. Accessed 19 Aug 2020.

43. Fauré, E., Finnveden, G., \& Gunnarsson-Östling, U. (2019). Four low-carbon futures for a Swedish society beyond GDP growth. Journal of Cleaner Production, 236(1), 1-13.

44. Długosz, P.M. (2014). The rise of the sharing city Examining origins and futures of urban sharing. In International Institute for Industrial Environmental Economics Master thesis 1-64.

45. Svenfelt, ^. (2019). Scenarios for sustainable futures beyond GDP growth 2050. Futures, 111, 1-14.

46. Geissinger, A., Laurell, C., Öberg, C., \& Sandström, C. (2019). How sustainable is the sharing economy? On the sustainability connotations of sharing economy platforms. Journal of Cleaner Production, 206, 419-429.

47. Bellgran, J. (2017). Sharing economy from a sustainability perspective. Bachelor Thesis in Political Science, Uppsala University, 1-40. (in Swedish).

48. Bergh, A., \& Funcke, A. (2016). Does country level social trust predict the size of the sharing economy? IFN Working Paper, 1130, 1-10.

49. Hammarlund, T., Sjunnesson, V. (2019). Where do we draw the line? How far different cultures are willing to adopt the concept of the sharing economy. Bachelor Thesis, 15 credits, for a Bachelor of Science in Business Administration: International Business and Marketing Spring 2019, 1-82.

50. Light, A., \& Seravalli, A. (2019). The breakdown of the municipality as caring platform: Lessons for co-design and co-learning in the age of platform capitalism. CoDesign, 15, 192-211.

51. Light, A., \& Miskelly, C. (2019). Platforms, scales and networks: Meshing a local sustainable sharing economy. Computer Supported Cooperative Work., 28, 591-626.

52. Laurell, C., \& Sandström, C. (2017). The sharing economy in social media: Analyzing tensions between market and non-market logics. Technological Forecasting Social Change, 125, 58-65.

53. Kristoffersson, E. (2019). How to tax the sharing economy. In Proceedings of the GSRD International Conference. Presented at the IRES-644th International Conference on E-Education, E-Business, E-management and E-learning, (IC4E), Seoul, South Korea, 20th-21st July 30-35.

54. Söderqvist, F. (2017). A Nordic approach to regulating intermediary online labour platforms. Transfer European Review of Labour and Research, 23, 349-352.

55. May, S., Köningsson, M., and Holmström, J. (2017). Unlocking the sharing economy: Investigating the barriers for the sharing economy in a city context, First Monday, 22(2). https://firstmonday.org/ ojs/index.php/fm/article/download/7110/5918. https://doi.org/10.5210/fm.v22i12.7110.

56. Andersson, M., Hjalmarsson, A., \& Avital, M. (2013). Peer-to-peer service sharing platforms: Driving share and share alike on a mass-scale. Proceedings of the 34th International Conference on Information Systems. (ICIS 2013) Reshaping Society Through Information Systems Design. Through Inf. Syst. Des. 4, 2964-2978.

57. Witt, A., Suzor, N., \& Wikström, P. (2015). Regulating ride-sharing in the peer economy. Communication Research and Practice, 1(2), 174-190.

58. Rodríguez, R., Svensson, G., \& del Pérez, M. M. (2017). Business models in the collaborative economy: Summary and suggestions. ESIC Esic Market Economics and Business Journal, 48(2), $235-254$.

59. Gullstrand, E. E., Lehner, M., \& Mont, O. (2016). Exploring consumer attitudes to alternative models of consumption: Motivations and barriers. Journal of Cleaner Production, 123, 5-15.

60. Lampinen, A., \& Brown, B. (2017). Market design for HCI: Successes and failures of peer-to-peer exchange platforms. Proceedings of Conference of Human Factors in Computing. Systems. 2017May, 4331-4343.

61. Lampinen, A., \& Cheshire, C. (2016). Hosting via airbnb: Motivations and financial assurances in monetized network hospitality. Proceedings of Conference of Human Factors in Computing. Systems, 2016-May, 1669-1680.

62. Fedosov, A., Dillahunt, T., Cheshire, C., Lampinen, A., Light, A. (2019). Cooperativism and human-computer interaction. Proceedings of Conference of Human Factors in Computing Systems 2019-May, $1-4$.

63. Pargman, D., Eriksson, E., \& Friday, A. (2016). Limits to the sharing economy. In: LIMITS'16: Proceedings of the Second Workshop on Computing within Limits, June 08-10, Irvine, CA, USA, 1-7. 
64. Hult, A., \& Bradley, K. (2017). Planning for sharing: Providing infrastructure for citizens to be makers and sharers. Planning Theory \& Practice, 18(4), 597-615.

65. Guyader, H. (2019). The heart and wallet paradox of collaborative consumption. Linköping Studies in Arts and Science No. 763 (Faculty of Arts and Sciences Linköping), 1-133.

66. Glöss, M., McGregor, M., \& Brown, B. (2016). Designing for labour: Uber and the on-demand mobile workforce. Proceedings of Conference of Human Factors in Computing. Systems, 2016-May, 1632-1643.

67. Gössling, S., \& Michael, H. C. (2019). Sharing versus collaborative economy: How to align ICT developments and the SDGs in tourism? Journal of Sustainable Tourism, 27(1), 74-96.

68. Markendahl, J., Hossain, M. I., Mccormick, K., Lund, T., Moller, J., \& Näslund, P. (2019). Analysis of sharing economy services: Initial findings from sharing cities Sweden. Nordic and Baltic Journal of Information and Communications Technologies, 1, 239-260.

69. Lobel, O. (2017). The gig economy \& the future of employment and labor law. University of San Francisco Law Review, 51, 51-74.

70. Yamazaki, K. (2018). A virtual image of new business model. Economy, 276, 53-62. (in Japanese).

Publisher's Note Springer Nature remains neutral with regard to jurisdictional claims in published maps and institutional affiliations. 